\title{
Surveillance and comparison of antimicrobial susceptibility patterns of ESKAPE organisms isolated from patients with bacteraemia in South Africa, 2016 - 2017
}

\author{
H Ismail, ${ }^{1}$ BSc, BSc Hons, PhD, MPH; W Lowman, ${ }^{2,3,4}$ MB BCh, FC Path (SA) (Microbiol), MMed (Microbiol); C N Govind, ${ }^{5,6}$ MB ChB, \\ FC Path (SA) (Microbiol); K Swe Swe-Han, ${ }^{6,7}$ MBBS, DTM\&H, PDIC, FC Path (SA) (Microbiol), MMed (Microbiol), PhD (Med Microbiol); \\ M R B Maloba, ${ }^{8}$ MB ChB, DTM\&H, FC Path (SA) (Microbiol); C Bamford, ${ }^{9,10}$ MB ChB, FC Path (SA) (Microbiol), MMed (Microbiol); \\ O Perovic, ${ }^{1,2}$ MD, DTM\&H, FC Path (SA) (Microbiol), MMed (Microbiol)

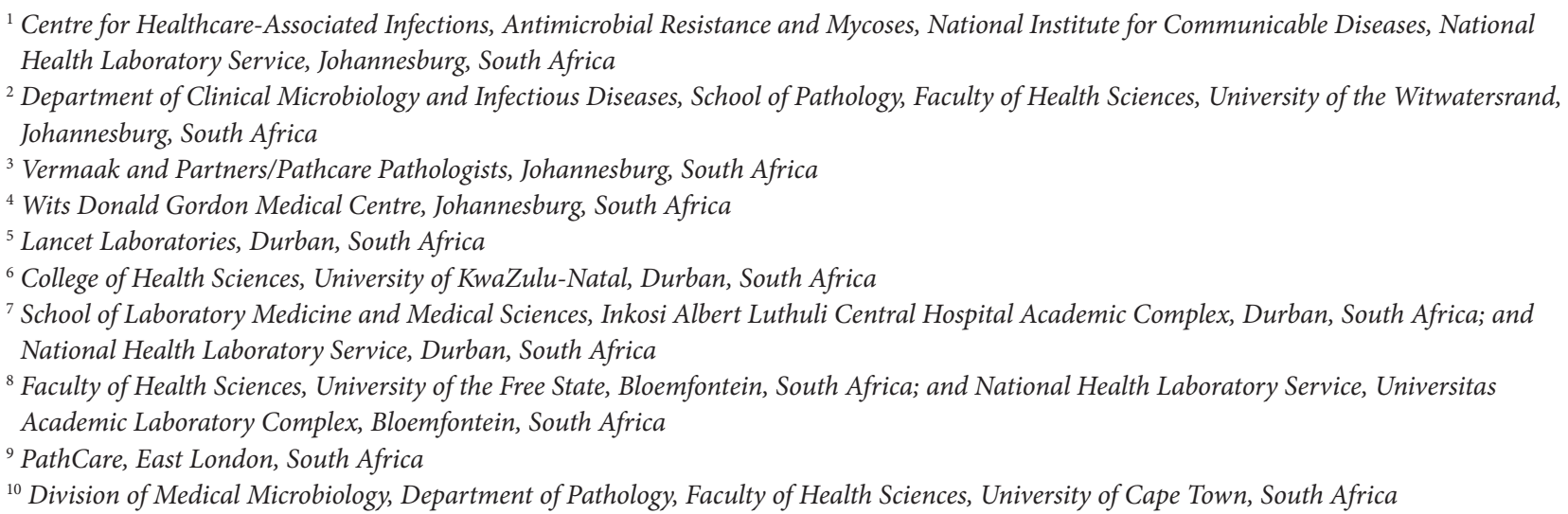

Corresponding author: O Perovic (olgap@nicd.ac.za)

\begin{abstract}
Background. In South Africa (SA), the National Department of Health has developed an Antimicrobial Resistance National Strategy Framework document to manage antimicrobial resistance (AMR). One of the strategic objectives is to optimise surveillance and early detection of AMR. At the National Institute for Communicable Diseases (NICD), an analysis of selected organisms and antimicrobial agents from both the public and the private sectors was conducted.

Objectives. The relevance of surveillance for AMR is increasingly recognised in the light of global action plans to combat resistance. In this report, we present an overview of ESKAPE (Enterococcus faecium, Staphylococcus aureus, Klebsiella pneumoniae, Acinetobacter baumannii, Pseudomonas aeruginosa, Enterobacter spp.) organisms and Escherichia coli reported from public and private sector laboratories in SA for the period $2016-2017$.

Methods. Antimicrobial susceptibility testing (AST) profiles on selected ESKAPE organisms and E. coli isolated from blood cultures from the public and private sectors in 2016 and 2017 were analysed. AST data were extracted from a web-based electronic platform created by the NICD. Drug-bug combinations following the World Health Organization's Global Antimicrobial Surveillance System guidelines were included in the analysis.

Results. A total of 28920 ESKAPE organisms and E. coli were reported in 2016 and 32293 in 2017 across the two health sectors. Proportions of some organisms differed between the two health sectors, such as E. coli (19\% in the public sector and $36 \%$ in the private sector), A. baumannii (14\% public and $4 \%$ private), P. aeruginosa ( $7 \%$ public and $11 \%$ private) and S. aureus (27\% public and $17 \%$ private) Susceptibility data indicated changing patterns in both sectors towards an increase in non-susceptibility to carbapenems in K. pneumoniae $(p<0.01)$. However, we demonstrated an increase in susceptibility to cloxacillin in $S$. aureus $(p<0.01)$ in both sectors.

Conclusions. The key clinically important finding is the rapidly decreasing carbapenem susceptibility among Enterobacteriaceae reported in SA, irrespective of sector. In addition, the analysis provides information that could be used to monitor the effectiveness of interventions implemented at a national level under the guidance and direction of the national AMR framework.
\end{abstract}

S Afr Med J 2019;109(12):934-940. https://doi.org/10.7196/SAMJ.2019.v109i12.14079

Antimicrobial resistance (AMR) among both Gram-positive and Gram-negative bacteria has increased in recent years. ${ }^{[1]}$ Bacteria in the ESKAPE group (Enterococcus faecium, Staphylococcus aureus, Klebsiella pneumoniae, Acinetobacter baumannii, Pseudomonas aeruginosa, Enterobacter spp.) account for two-thirds of all healthcareassociated infections and have been shown to display high rates of
AMR. ${ }^{[2]}$ Gram-negative ESKAPE organisms are of concern owing to their multidrug-resistant phenotypes, which generally present clinicians with few treatment options. ${ }^{[3]}$ Surveillance for AMR is pivotal to understanding the extent of resistance at individual facilities and at the national level. Surveillance reports provide guidance for antibiotic treatment at local and national levels. Surveillance is an 
important strategy in the South African (SA) National Department of Health and features in the Antimicrobial Resistance National Strategy Framework document as one of the strategic objectives to optimise surveillance and early detection of AMR. At the National Institute for Communicable Diseases (NICD), an analysis of selected organisms and antimicrobial agents from both the public and the private health sectors was conducted.

\section{Objectives}

To describe the spectrum of selected ESKAPE organisms as well as Escherichia coli isolated from patients with bacteraemia reported from the two health sectors in SA and to compare their antimicrobial susceptibility testing (AST) profiles over a 2-year period.

\section{Methods}

Secondary data analysis was conducted from January 2016 to December 2017. AST data were extracted from a secure web-based electronic platform created by the Surveillance Information Management Unit at the NICD. These data were available on the AMR dashboard from the NICD website (http://www.nicd.ac.za). The study population included all patients who had a blood culture submitted either to the public National Health Laboratory Service or to one of the four accredited private pathology laboratories (Ampath, Lancet Laboratories, PathCare and Vermaak and Partners). Positive blood cultures with any one of the ESKAPE organisms or E. coli were included in the analysis. A working group of the South African Society for Clinical Microbiology made a decision in 2015 not to include surveillance of Enterobacter spp. owing to concerns about lack of standardisation in the testing and reporting of susceptibility profiles between different laboratories. In line with the GERMS-SA laboratory-based surveillance programmes, duplicate isolates obtained from the same patient within 21 days were excluded in order to avoid bias due to over-representation of sicker patients undergoing multiple investigations. AST and interpretation of results were performed by individual laboratories according to current Clinical and Laboratory Standards Institute (CLSI) guidelines, ${ }^{[4]}$ or European Committee on Antimicrobial Susceptibility Testing (EUCAST) guidelines ${ }^{[5]}$ at one private laboratory. There were only a few minor changes in the breakpoint interpretation in EUCAST during the 2 years of the study (for example, cefepime zone sizes were changed from $19 \mathrm{~mm}$ to $21 \mathrm{~mm}$ ), and no changes in CLSI have been indicated for drug-bug combinations analysed in in this article. Data were omitted for hospitals that tested $<30$ organisms for a particular antimicrobial agent. In the secondary data analysis, AST results were grouped based on categorical data as provided by the submitting laboratories. Results were reported as susceptible or nonsusceptible, which includes the intermediate and resistant categories. Reporting of susceptibility profiles for drug-bug combinations was based on the Global Antimicrobial Surveillance System (GLASS) early implementation manual. ${ }^{[6]}$ Absolute frequencies, percentages, bar charts and tables were used to describe the data. The $\chi^{2}$ test was used to compare differences among AST patterns over the 2-year period, with the level of significance set at $p<0.05$.

\section{Results}

A total of 28920 ESKAPE organisms and E. coli were reported in 2016 and 32293 in 2017 across the two health sectors in SA. The proportion of E. coli was $19 \%$ in the public sector and $36 \%$ in the private sector, that of $K$. pneumoniae was $27 \%$ in the public sector and $30 \%$ in the private sector, that of $A$. baumannii was $14 \%$ in the public sector and $4 \%$ in the private sector, that of P. aeruginosa was $7 \%$ in the public sector and $11 \%$ in the private sector, that of E. faecium was $8 \%$ in the public sector and $4 \%$ in the private sector, and that of $S$. aureus was $27 \%$ in the public sector and $17 \%$ in the private sector (Fig. 1).

\section{Enterobacteriaceae \\ E. coli}

The bacterial profile for E. coli reported over the 2-year period showed notable differences in the proportions across the two health sectors. For the public sector, the proportion was similar over the 2 years, $19 \%$ (3 981/20 630) in 2016 and $19 \%$ (4 085/21 124) in 2017. However, in the private sector, there was an increase in the proportion of reported E. coli from 34\% (2 781/8 290) in 2016 to 37\% (4 187/11 169) in 2017 (Fig. 1). Comparison of the AST profiles for the fluoroquinolone ciprofloxacin showed no change in the public sector (74\%), but in the private sector there was a significant decrease in susceptibility from $69 \%$ to $65 \%$ $(p<0.01)$. Although no significant changes were noted for the thirdgeneration cephalosporins cefotaxime/ceftriaxone and ceftazidime and the fourth-generation cephalosporin cefepime, higher susceptibility was noted for isolates reported from the private sector compared with the public sector. High proportions of isolates ( $\geq 99 \%)$ reported from both health sectors were susceptible to the carbapenems ertapenem, imipenem and meropenem. No significant changes in susceptibility profiles were observed for the beta-lactam and beta-lactamase inhibitor piperacillin-tazobactam in either health sector (Table 1).

\section{K. pneumoniae}

The bacterial profile for $K$. pneumoniae reported over the 2-year period was similar for the two health sectors: $27 \%$ (5 533/20 630) in the public sector in 2016 and 26\% (5 440/21 124) in 2017, and 30\% (2 466/8 290) in the private sector in 2016 and 29\% (3 204/11 169) in 2017 (Fig. 1). AST profiles for ciprofloxacin reported from both health sectors showed a significant decrease in susceptibility, from $66 \%$ to $64 \%$ in the public sector $(p=0.04$ ) and from $60 \%$ to $54 \%$ in the private sector $(p<0.01)$. Significant decreases in susceptibilities were noted for the carbapenems in both health sectors. In the public sector, ertapenem decreased from $96 \%$ to $92 \%(p<0.01)$, imipenem from $95 \%$ to $91 \%(p<0.01)$ and meropenem from $94 \%$ to $91 \%(p<0.01)$, and in the private sector, ertapenem decreased from $85 \%$ to $77 \%(p<0.01)$, imipenem from $90 \%$ to $85 \%(p<0.01)$ and meropenem from $91 \%$ to $86 \%(p<0.01)$. No significant changes in susceptibility to piperacillintazobactam were noted for isolates reported from the public sector, but isolates reported from the private sector showed a significant decrease from $43 \%$ to $37 \%(p<0.01)$ (Table 2$)$.

\section{Non-fermentative Gram-negative bacteria A. baumannii}

The bacterial profile for A. baumannii reported over the 2-year period showed a $\sim 10 \%$ difference in the proportion of isolates reported by the two health sectors: 13\% (2 736/20 630) in 2016 and 15\% (3 139/21 $124)$ in 2017 in the public sector and 4\% (304/8 290) in 2016 and $4 \%(458 / 11169)$ in 2017 in the private sector (Fig. 1). A significant decrease in susceptibility to the aminoglycosides (amikacin from $44 \%$ to $37 \%(p<0.01)$ and gentamicin from $32 \%$ to $23 \%(p<0.01))$ was observed in isolates reported from the public sector. Although a decrease in susceptibility was noted for isolates reported from the private sector (amikacin from 63\% to 57\% $(p=0.08)$ and gentamicin from $53 \%$ to $46 \%(p=0.06)$ ), these differences were not significant $(p \geq 0.05)$ (Table 3). Significant decreases in susceptibilities were noted for the carbapenems reported from both health sectors: imipenem from $27 \%$ to $19 \%(p<0.01)$ and meropenem from $25 \%$ to $19 \%(p<0.01)$ in the public sector and imipenem from $46 \%$ to $38 \%(p=0.03)$ and meropenem from $44 \%$ to $38 \%(p=0.09)$ in the private sector (Table 3 ). 


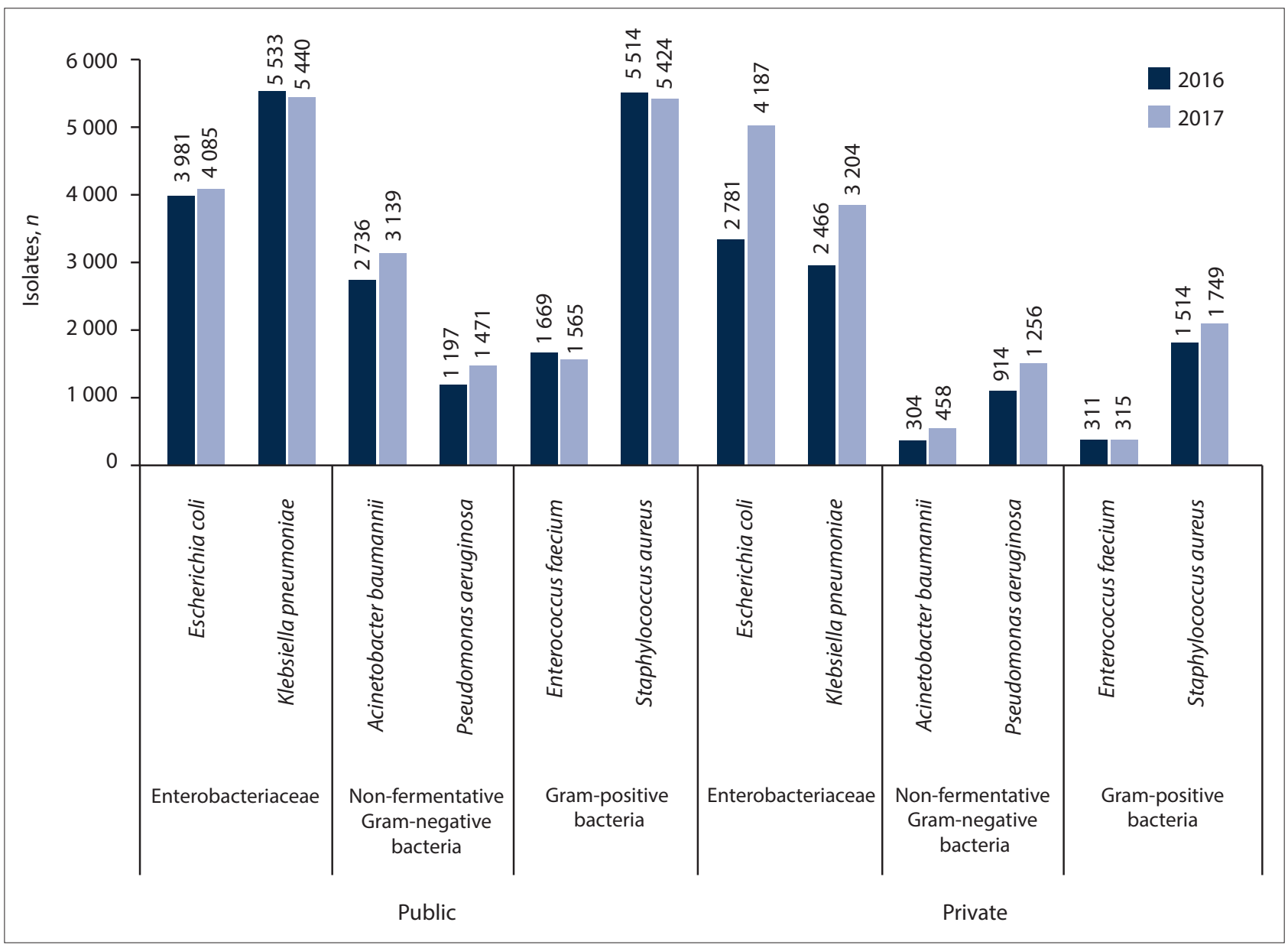

Fig. 1. Bacterial profile for ESKAPE organisms (Enterococcus faecium, Staphylococcus aureus, Klebsiella pneumoniae, Acinetobacter baumannii, Pseudomonas aeruginosa, Enterobacter spp.) and Escherichia coli identified from blood cultures from public and private health sectors in South Africa, 2016 - 2017.

\section{P. aeruginosa}

The bacterial profile for $P$. aeruginosa reported over the 2-year period showed a $\sim 5 \%$ difference in the proportion of isolates reported by the two health sectors. The absolute numbers of reported cases were approximately the same: 6\% (1 197/20 630) in 2016 and $7 \%$ ( $1471 / 21$ 124) in 2017 in the public sector and $11 \%$ (914/8 290) in 2016 and $11 \%$ (1 256/11 169) in 2017 in the private sector (Fig. 1). A significant increase in susceptibility to ceftazidime from $79 \%$ to $84 \%$ was noted for isolates reported from the public sector $(p<0.01)$. Isolates reported from the public sector showed no significant changes in susceptibility to imipenem and meropenem. However, a significant decrease in susceptibility was observed for isolates reported from the private sector: imipenem from $62 \%$ to $58 \%(p=0.04)$ and meropenem from $64 \%$ to $60 \% \quad(p=0.03)$. Although isolates reported from the private sector displayed similar susceptibility patterns to piperacillin-tazobactam, isolates reported from the public sector showed a significant increase in susceptibility from $73 \%$ to $81 \%(p<0.01)$ (Table 4$)$.

\section{Gram-positive bacteria}

\section{E. faecium}

The bacterial profile for E. faecium reported over the 2-year period showed notable differences in proportions across the two health sectors. For the public sector, the proportion was similar, $8 \%$ (1 669/20 630) in 2016 and 7\% (1 565/21 124) in 2017, and was shown to be higher than in the private sector, where it was $4 \%$
(311/8 290) in 2016 and 3\% (315/11 169) in 2017 (Fig. 1). Although a high proportion of isolates reported from both health sectors were susceptible to both vancomycin and teicoplanin, a significant decrease in susceptibility to teicoplanin was noted for isolates in the public sector, from $97 \%$ to $94 \%(p<0.01)$. No changes in susceptibility patterns were noted for linezolid during the 2 years (Table 5 ).

\section{S. aureus}

The bacterial profile for $S$. aureus reported over the 2-year period showed notable differences in the proportions across the two health sectors. For the public sector the proportion was similar, 27\% (5 514/20 630) in 2016 and $26 \%(5424 / 21$ 124) in 2017, and the figures were lower in the private sector, $18 \%$ (1 514/8 290) in 2016 and $16 \%(1749 / 11169)$ in 2017 (Fig. 1). A significant increase in susceptibility to the penicillinase-stable penicillin cloxacillin was observed in both sectors, from $72 \%$ to $77 \%$ in the public sector $(p<0.01)$ and from $74 \%$ to $85 \%$ in the private sector $(p<0.01)$. A general observation was that a greater proportion of cloxacillinsusceptible $S$. aureus isolates was reported in the private sector compared with the public sector in 2017 (Table 6).

\section{Discussion}

This report describes and compares AST profiles for ESKAPE organisms and E. coli isolated from blood cultures over a 2-year period in the public and private health sectors in SA. The majority of isolates were reported from the public sector (71\% (20 630/28 920) 


\begin{tabular}{|c|c|c|c|c|c|c|}
\hline \multirow[b]{2}{*}{ Health sector } & \multirow[b]{2}{*}{ Drug } & \multicolumn{2}{|c|}{2016} & \multicolumn{2}{|r|}{2017} & \multirow[b]{2}{*}{$p$-value } \\
\hline & & $\begin{array}{l}\text { Total } \\
\text { isolates } \\
\text { tested, } N\end{array}$ & $\begin{array}{l}\text { Susceptible, } \\
n(\%)\end{array}$ & $\begin{array}{l}\text { Total isolates } \\
\text { tested, } N\end{array}$ & Susceptible, $n(\%)$ & \\
\hline \multirow[t]{14}{*}{ Public } & Amikacin & 3842 & $3478(91)$ & 3885 & $3522(91)$ & 0.84 \\
\hline & Amoxicillin-clavulanic acid & 3845 & $2462(64)$ & 3870 & $2456(63)$ & 0.60 \\
\hline & Ampicillin/amoxicillin & 3834 & $614(16)$ & 3823 & $595(16)$ & 0.59 \\
\hline & Cefepime & 3668 & $2785(76)$ & 3750 & $2825(75)$ & 0.55 \\
\hline & Cefotaxime/ceftriaxone & 3752 & $2798(75)$ & 3835 & $2874(75)$ & 0.71 \\
\hline & Ceftazidime & 3780 & $2869(76)$ & 3791 & $2848(75)$ & 0.43 \\
\hline & Ciprofloxacin & 3815 & $2818(74)$ & 3720 & $2756(74)$ & 0.83 \\
\hline & Co-trimoxazole & NT & NT & NT & NT & - \\
\hline & Doripenem & NT & NT & NT & NT & - \\
\hline & Ertapenem & 3552 & $3518(99)$ & 3659 & $3645(100)$ & $<0.01^{*}$ \\
\hline & Gentamicin & 3864 & $3168(82)$ & 3872 & $3175(82)$ & 0.99 \\
\hline & Imipenem & 3727 & 3705 (99) & 3774 & $3757(100)$ & 0.40 \\
\hline & Meropenem & 3716 & $3691(99)$ & 3810 & $3791(100)$ & 0.32 \\
\hline & Piperacillin-tazobactam & 3485 & $3020(87)$ & 3736 & $3237(87)$ & 0.99 \\
\hline \multirow[t]{15}{*}{ Private } & Amikacin & 2781 & $2598(93)$ & 4040 & 3725 (92) & 0.06 \\
\hline & Amoxicillin-clavulanic acid & 2780 & $1945(70)$ & 4171 & $2791(67)$ & 0.01 \\
\hline & Ampicillin/amoxicillin & 1998 & $425(21)$ & 2310 & $466(20)$ & 0.38 \\
\hline & Cefepime & 2778 & $2283(82)$ & 4040 & $3254(81)$ & 0.09 \\
\hline & Cefotaxime/ceftriaxone & 2777 & $2253(81)$ & 4171 & $3329(80)$ & 0.18 \\
\hline & Ceftazidime & 2148 & $1755(82)$ & 2804 & $2231(80)$ & 0.06 \\
\hline & Ciprofloxacin & 1997 & $1378(69)$ & 3534 & $2301(65)$ & $<0.01$ \\
\hline & Co-trimoxazole & 1746 & $657(38)$ & 2298 & $839(37)$ & 0.47 \\
\hline & Doripenem & 2753 & $2748(100)$ & 4013 & $4007(100)$ & 0.75 \\
\hline & Ertapenem & 2779 & $2769(100)$ & 4041 & $4026(100)$ & 0.94 \\
\hline & Gentamicin & 2779 & $2368(85)$ & 4045 & $3448(85)$ & 0.97 \\
\hline & Imipenem & 2777 & $2772(100)$ & 4043 & $4033(100)$ & 0.61 \\
\hline & Levofloxacin & 792 & $593(75)$ & 1229 & $868(71)$ & 0.04 \\
\hline & Meropenem & 2780 & $2777(100)$ & 4042 & $4034(100)$ & 0.54 \\
\hline & Piperacillin-tazobactam & 2774 & $2212(80)$ & 3677 & $2868(78)$ & 0.09 \\
\hline
\end{tabular}

in 2016 and 65\% (21 124/32 293) in 2017), demonstrating the public laboratory coverage of $~ 80 \%$ of the general population; however, this ratio still reflects under-utilisation of blood culture diagnostics in the public sector.

Gram-negative bacteria were reported more commonly than Gram-positive ones in both the public sector (65\% (13 447/20 630) in 2016 and $67 \%$ (14 135/21 124) in 2017) and the private sector (78\% (6 465/8 290) in 2016 and 82\% (9 105/11 169) in 2017). We also observed a different bacterial profile for the two sectors. In the public sector, higher proportions of E. faecium, A. baumannii and $S$. aureus were reported, while in the private sector there were higher proportions of $P$. aeruginosa and E. coli. The present report only described the susceptibility profiles of organisms, and not demographic or clinical data. It was therefore not possible to determine the reasons for this difference. Possible causes may include differences in specimen-taking practices, differences in infection control practices and different patient populations.

In the Enterobacteriaceae group, E. coli showed no noteworthy differences in susceptibility profile in the public sector. However, a significant decrease in susceptibility to ciprofloxacin and amoxicillinclavulanic acid was observed in the private sector, possibly owing to excessive use of these agents in treatment of the most common urinary and respiratory infections.

$K$. pneumoniae demonstrated decreased susceptibility to many antibiotics $(p<0.01)$ in both sectors, suggesting possible overuse of broad-spectrum antibiotics or lack of infection prevention and control. The most striking finding was a decrease in susceptibility to the carbapenems, with both sectors showing a significant difference just a year apart $(p<0.01)$. This increase in carbapenem-resistant Enterobacteriaceae (CRE) is largely attributable to the increase in isolates harbouring carbapenemase-producing genes. ${ }^{[7]} \mathrm{A}$ number of factors may have influenced this change, including poor infection prevention and control measures targeting CRE, lack of effective antimicrobial stewardship programmes, or possible emergence of a successful clone. ${ }^{[8]}$

Antimicrobial susceptibility of A. baumannii indicated a significant decrease in susceptibility to aminoglycosides and carbapenems in the public sector, possibly owing to use of these agents in the treatment of infections by $K$. pneumoniae and other Enterobacteriaceae. In contrast, the only observed significant change in antimicrobial susceptibility of A. baumannii in the private sector was decreased susceptibility to the carbapenem imipenem. 


\begin{tabular}{|c|c|c|c|c|c|c|}
\hline \multirow[b]{2}{*}{ Health sector } & \multirow[b]{2}{*}{ Drug } & \multicolumn{2}{|c|}{2016} & \multicolumn{2}{|r|}{2017} & \multirow[b]{2}{*}{$p$-value } \\
\hline & & $\begin{array}{l}\text { Total } \\
\text { isolates } \\
\text { tested, } N\end{array}$ & $\begin{array}{l}\text { Susceptible, } \\
n(\%)\end{array}$ & $\begin{array}{l}\text { Total isolates } \\
\text { tested, } N\end{array}$ & Susceptible, $n(\%)$ & \\
\hline \multirow[t]{14}{*}{ Public } & Amikacin & 5288 & $4278(81)$ & 5130 & $4164(81)$ & 0.73 \\
\hline & Amoxicillin-clavulanic acid & 5284 & $1763(33)$ & 5085 & $1542(30)$ & $<0.01$ \\
\hline & Cefepime & 5164 & $1687(33)$ & 5012 & $1548(31)$ & 0.05 \\
\hline & Cefotaxime/ceftriaxone & 5192 & $1631(31)$ & 5008 & $1483(30)$ & 0.05 \\
\hline & Ceftazidime & 5201 & $1661(32)$ & 5042 & $1523(30)$ & 0.06 \\
\hline & Ciprofloxacin & 5280 & $3479(66)$ & 4893 & $3128(64)$ & 0.04 \\
\hline & Co-trimoxazole & NT & NT & NT & NT & - \\
\hline & Doripenem & NT & NT & NT & NT & - \\
\hline & Ertapenem & 4769 & $4562(96)$ & 4696 & $4333(92)$ & $<0.01$ \\
\hline & Gentamicin & 5308 & $2083(39)$ & 5125 & $1992(39)$ & 0.70 \\
\hline & Imipenem & 5071 & $4800(95)$ & 4929 & $4492(91)$ & $<0.01$ \\
\hline & Levofloxacin & 48 & $35(73)$ & 38 & $22(58)$ & 0.14 \\
\hline & Meropenem & 5068 & $4772(94)$ & 4967 & $4537(91)$ & $<0.01$ \\
\hline & Piperacillin-tazobactam & 4967 & $2799(56)$ & 4951 & $2718(55)$ & 0.15 \\
\hline \multirow[t]{14}{*}{ Private } & Amikacin & 2444 & $1964(80)$ & 3162 & $2392(76)$ & $<0.01$ \\
\hline & Amoxicillin-clavulanic acid & 2450 & $975(40)$ & 3175 & $1133(36)$ & $<0.01$ \\
\hline & Cefepime & 2435 & $1070(44)$ & 3167 & $1231(39)$ & $<0.01$ \\
\hline & Cefotaxime/ceftriaxone & 2442 & $1052(43)$ & 3169 & $1203(38)$ & $<0.01$ \\
\hline & Ceftazidime & 1760 & $789(45)$ & 2307 & $895(39)$ & $<0.01$ \\
\hline & Ciprofloxacin & 2068 & $1231(60)$ & 2824 & $1528(54)$ & $<0.01$ \\
\hline & Co-trimoxazole & 1853 & $789(43)$ & 2625 & $1027(39)$ & 0.02 \\
\hline & Doripenem & 2376 & $2185(92)$ & 3047 & $2683(88)$ & $<0.01$ \\
\hline & Ertapenem & 2419 & $2056(85)$ & 3124 & $2403(77)$ & $<0.01$ \\
\hline & Gentamicin & 2442 & $1405(58)$ & 3169 & $1727(54)$ & 0.02 \\
\hline & Imipenem & 2410 & $2175(90)$ & 3121 & $2647(85)$ & $<0.01$ \\
\hline & Levofloxacin & 509 & $382(75)$ & 551 & $378(69)$ & 0.02 \\
\hline & Meropenem & 2431 & $2206(91)$ & 3123 & $2679(86)$ & $<0.01$ \\
\hline & Piperacillin-tazobactam & 2443 & $1050(43)$ & 3169 & $1184(37)$ & $<0.01$ \\
\hline
\end{tabular}

Table 3. Antimicrobial susceptibility patterns of Acinetobacter baumannii isolates identified from blood cultures in South Africa, 2016 - 2017

\begin{tabular}{|c|c|c|c|c|c|c|}
\hline \multirow[b]{2}{*}{ Health sector } & \multirow[b]{2}{*}{ Drug } & \multicolumn{2}{|c|}{2016} & \multicolumn{2}{|c|}{2017} & \multirow[b]{2}{*}{$p$-value } \\
\hline & & $\begin{array}{l}\text { isolates } \\
\text { tested, } N\end{array}$ & $\begin{array}{l}\text { Susceptible, } \\
n(\%)\end{array}$ & $\begin{array}{l}\text { Total isolates } \\
\text { tested, } N\end{array}$ & Susceptible, $n(\%)$ & \\
\hline \multirow[t]{7}{*}{ Public } & Amikacin & 2064 & $913(44)$ & 2052 & $765(37)$ & $<0.01$ \\
\hline & Doripenem & NT & NT & NT & NT & \\
\hline & Gentamicin & 2629 & $837(32)$ & 2955 & $668(23)$ & $<0.01$ \\
\hline & Imipenem & 2581 & $684(27)$ & 2865 & $558(19)$ & $<0.01$ \\
\hline & Meropenem & 2602 & $654(25)$ & 2928 & 549 (19) & $<0.01$ \\
\hline & Minocycline & 30 & $6(20)$ & 33 & $9(27)$ & 0.56 \\
\hline & Tigecycline & 1279 & $1176(92)$ & 1745 & $1585(91)$ & 0.28 \\
\hline \multirow[t]{7}{*}{ Private } & Amikacin & 288 & $182(63)$ & 439 & $249(57)$ & 0.08 \\
\hline & Doripenem & 275 & $120(44)$ & 435 & $172(40)$ & 0.28 \\
\hline & Gentamicin & 303 & $161(53)$ & 458 & $212(46)$ & 0.06 \\
\hline & Imipenem & 304 & $139(46)$ & 458 & $174(38)$ & 0.03 \\
\hline & Meropenem & 303 & $133(44)$ & 458 & $173(38)$ & 0.09 \\
\hline & Minocycline & NT & NT & NT & NT & - \\
\hline & Tigecycline & 212 & $190(90)$ & 326 & $285(87)$ & 0.44 \\
\hline
\end{tabular}




\begin{tabular}{|c|c|c|c|c|c|c|}
\hline \multirow[b]{2}{*}{ Health sector } & \multirow[b]{2}{*}{ Drug } & \multicolumn{2}{|c|}{2016} & \multicolumn{2}{|r|}{2017} & \multirow[b]{2}{*}{$p$-value } \\
\hline & & $\begin{array}{l}\text { Total } \\
\text { isolates } \\
\text { tested, } N\end{array}$ & $\begin{array}{l}\text { Susceptible, } \\
n(\%)\end{array}$ & $\begin{array}{l}\text { Total isolates } \\
\text { tested, } N\end{array}$ & Susceptible, $n(\%)$ & \\
\hline \multirow[t]{6}{*}{ Public } & Cefepime & 1076 & $884(82)$ & 1324 & $1119(85)$ & 0.12 \\
\hline & Ceftazidime & 1150 & $906(79)$ & 1404 & $1173(84)$ & $<0.01$ \\
\hline & Doripenem & NT & NT & NT & NT & - \\
\hline & Imipenem & 1102 & $845(77)$ & 1362 & $1040(76)$ & 0.85 \\
\hline & Meropenem & 1123 & $873(78)$ & 1372 & $1063(77)$ & 0.88 \\
\hline & Piperacillin/tazobactam & 1118 & $812(73)$ & 1369 & $1112(81)$ & $<0.01$ \\
\hline \multirow[t]{6}{*}{ Private } & Cefepime & 908 & $652(72)$ & 1240 & $862(70)$ & 0.25 \\
\hline & Ceftazidime & 892 & $657(74)$ & 1228 & $876(71)$ & 0.24 \\
\hline & Doripenem & 883 & $601(68)$ & 1208 & $762(63)$ & 0.02 \\
\hline & Imipenem & 911 & $567(62)$ & 1243 & $719(58)$ & 0.04 \\
\hline & Meropenem & 912 & $588(64)$ & 1244 & $745(60)$ & 0.03 \\
\hline & Piperacillin/tazobactam & 902 & $582(65)$ & 1226 & $780(64)$ & 0.67 \\
\hline
\end{tabular}

Table 5. Antimicrobial susceptibility patterns of Enterococcus faecium isolates identified from blood cultures in South Africa, 2016 - 2017

\begin{tabular}{|c|c|c|c|c|c|c|}
\hline \multirow[b]{2}{*}{ Health sector } & \multirow[b]{2}{*}{ Drug } & \multicolumn{2}{|c|}{2016} & \multicolumn{2}{|r|}{2017} & \multirow[b]{2}{*}{$p$-value } \\
\hline & & $\begin{array}{l}\text { Total } \\
\text { isolates } \\
\text { tested, } N\end{array}$ & $\begin{array}{l}\text { Susceptible, } \\
n(\%)\end{array}$ & $\begin{array}{l}\text { Total isolates } \\
\text { tested, } N\end{array}$ & Susceptible, $\boldsymbol{n}(\%)$ & \\
\hline \multirow[t]{5}{*}{ Public } & Daptomycin & NT & NT & NT & NT & - \\
\hline & Linezolid & 1380 & 1369 (99) & 1236 & 1224 (99) & 0.64 \\
\hline & Penicillin/ampicillin & 837 & $30(4)$ & 813 & $46(6)$ & 0.05 \\
\hline & Teicoplanin & 1033 & $1001(97)$ & 908 & $853(94)$ & $<0.01$ \\
\hline & Vancomycin & 1636 & $1560(95)$ & 1509 & $1436(95)$ & 0.80 \\
\hline \multirow[t]{5}{*}{ Private } & Daptomycin & 65 & $63(97)$ & 104 & $102(98)$ & 0.64 \\
\hline & Linezolid & 215 & $210(98)$ & 191 & $190(99)$ & 0.22 \\
\hline & Penicillin/ampicillin & 38 & $3(8)$ & 27 & 0 & 0.26 \\
\hline & Teicoplanin & 295 & $283(96)$ & 299 & $282(94)$ & 0.36 \\
\hline & Vancomycin & 309 & $295(95)$ & 312 & $294(94)$ & 0.49 \\
\hline $\mathrm{NT}=$ not tested. & & & & & & \\
\hline
\end{tabular}

Table 6. Antimicrobial susceptibility patterns of Staphylococcus aureus isolates identified from blood cultures in South Africa, 2016 - 2017

\begin{tabular}{|c|c|c|c|c|c|c|}
\hline \multirow[b]{2}{*}{ Health sector } & \multirow[b]{2}{*}{ Drug } & \multicolumn{2}{|c|}{2016} & \multicolumn{2}{|c|}{2017} & \multirow[b]{2}{*}{$p$-value } \\
\hline & & Total isolates tested, $N$ & Susceptible, $n(\%)$ & Total isolates tested, $N$ & Susceptible, $n(\%)$ & \\
\hline Public & Cloxacillin & 5118 & $3705(72)$ & 5108 & $3951(77)$ & $<0.01$ \\
\hline Private & Cloxacillin & 1283 & $950(74)$ & 1508 & $1283(85)$ & $<0.01$ \\
\hline
\end{tabular}

P. aeruginosa demonstrated significant increases in susceptibility to piperacillin/tazobactam and ceftazidime in the private sector, which may be explained by the infrequent use of these agents as empirical treatment.

Equally, we are seeing changing patterns in susceptibility to penicillinase-stable penicillins in $S$. aureus in both sectors, with subsequent reduced rates of methicillin-resistant S. aureus (MRSA). Absolute numbers of $S$. aureus did not decline, suggesting that the decrease in MRSA proportions may be due to a strain replacement with Gram-negative organisms in the proportion of hospital-acquired infections, a decrease in the prevalence of particularly pathogenic MRSA clones, or a combination of these two factors. The widening gap in MRSA proportions between the two sectors over the 2 years suggests that these factors are operating to different extents in the two sectors.

The second GLASS report presented AMR data from nine countries in the African region. Nigeria reported data on E. coli and $K$. pneumoniae showing $<25 \%$ susceptibility to third-generation cephalosporins from three sentinel sites, similar to our results for K. pneumoniae but not for E. coli. In contrast, susceptibility to third-generation cephalosporins in the UK is much higher, at 90\% for both organisms in 2017. ${ }^{[9]}$ AST findings for the ESKAPE organisms reported from the public sector in the present study were comparable to findings from an SA study published in 2018. ${ }^{[10]}$ In the present study, K. pneumoniae showed decreased susceptibility to carbapenems over the 2-year period, but susceptibility in isolates 
reported from secondary and tertiary health facilities from 2015 to 2016 remained constant. ${ }^{[10]}$ A. baumannii showed a notable decrease in susceptibility to the aminoglycosides: amikacin from $50 \%$ in 2015 to $40 \%$ in 2016 and gentamicin from $32 \%$ in 2015 to $28 \%$ in $2016 .{ }^{[10]}$ A decrease in susceptibility to teicoplanin was noted for E. faecium in the present study; however, susceptibility in isolates reported from the earlier study showed no change (97\%) from 2015 to 2016. ${ }^{[10]}$ Changing AST patterns to penicillinase-stable penicillins were also noted for S. aureus isolates. Both the present study and the earlier study showed increased susceptibility. ${ }^{[10,11]}$

This report indicates the importance of antimicrobial resistance surveillance for clinical treatment guidelines at the national level. At facility level there is a need for local antimicrobial susceptibility data to address antibiotic treatment appropriately. Specimen submission practices are important when addressing and analysing antimicrobial susceptibility patterns at each facility.

\section{Study limitations}

Findings from this study should be interpreted with caution. Its limitations have been highlighted in previous reports. ${ }^{[9,10]}$ Briefly, these include:

- Data may have been incomplete owing to missing information not captured on the laboratory information system or nonstandardised coding of ESKAPE organisms and antimicrobial agents at diagnostic laboratories.

- Testing methods and microbiological practice may have varied between laboratories, which could account for variations in the results presented in this report.

- Confirmatory AST methods were not performed or recorded for any of the ESKAPE organisms, as the results presented here were reported as captured on the laboratory information system by diagnostic laboratories. We have not been able to report on colistin AST, as new methods have been recommended by the CLSI and EUCAST guidelines, which were not universally implemented by all diagnostic laboratories during the period of the study.

- Data from the private sector represent a small (25-30\%) proportion of the general population and may not be directly comparable with the much greater proportion in the public sector owing to factors such as selective testing, specimen-taking practices, infection control practices and patient populations that may differ between the two sectors.

- Vancomycin non-susceptibility for S. aureus requires confirmatory testing, which is not available at routine laboratory level. All S. aureus isolates that are non-susceptible to vancomycin should be referred to reference laboratories for confirmation.

- Results for carbapenemase-producing Enterobacteriaceae are not available in this report, as not all CRE isolates are tested for carbapenemase-producing genes.

- AST results for Enterobacter spp. were not reported in this study.

\section{Conclusions}

This study provides important laboratory data to monitor AST profiles of ESKAPE organisms. The key clinically important finding is the rapidly decreasing carbapenem susceptibility among
Enterobacteriaceae reported in SA, irrespective of sector. High numbers and rates of resistance in A. baumannii are alarming in the public sector as this drives the use of colistin, the last resource for treatment of multidrug-resistant organisms. In addition, the study provides baseline surveillance data that can be used to monitor the effectiveness of interventions implemented at a national level under the guidance and direction of the national AMR framework.

\section{Declaration. None.}

Acknowledgements. The authors thank Sue Candy and her team from the Surveillance Information Management Unit at the NICD for making the data available and the South African Society for Clinical Microbiology editorial committee (N Govender, C Sriruttan, K Moodley, I Zietsman, B Magazi, R Kularatne and Y Mahabeer) for comments and suggestions. Author contributions. All authors contributed significantly to this paper. $\mathrm{HI}$ and OP: design, data analysis, interpretation of results and manuscript preparation. WL, CNG, KSS-H, MRBM, CB: editing, interpretation of results and manuscript preparation.

Funding. This study was supported by the NICD Centre for HealthcareAssociated Infections, Antimicrobial Resistance and Mycoses (CHARM). Conflicts of interest. None.

Disclaimer. Data reported in this study were received through the Surveillance Information Management Unit at the NICD. No demographic, epidemiological, clinical or molecular data were available to distinguish between healthcare-associated and community-associated infections. CHARM was not responsible for testing or reporting of results at patient level.

1. Llaca-Diaz JM, Mendoza-Olazaran S, Camacho-Ortiz A, Flores S, Garza-Gonzalez E. One-yea surveillance of ESKAPE pathogens in an intensive care unit of Monterrey, Mexico. Chemotherapy 2012;58(6): $475-481$. https://doi.org/10.1159/000346352

2. Saipriya JB, Shubha DS, Sudhindra KS, Sumantha A, Madhur KR. Clinical importance of emerging ESKAPE pathogens and antimicrobial susceptibility profile from a tertiary care centre. Int J Curr Microbiol Appl Sci 2018;7(5):2881-2891. https://doi.org/10.20546/ijcmas.2018.705.336

3. Karlowsky JA, Hoban DJ, Hackel MA, Lob SH, Sahm DF. Antimicrobial susceptibility of Gramnegative ESKAPE pathogens isolated from hospitalized patients with intra-abdominal and urinary tract infections in Asia-Pacific countries: SMART 2013 - 2015. J Med Microbiol 2017;66(1):61-69. https://doi. org/10.1099/jmm. 0.000421

4. Clinical and Laboratory Standards Institute (CLSI). Performance Standards for Antimicrobial Clinical and Laboratory Standards Institute (CLSI). Performance Standards for Antimicrobial
Susceptibility Testing. 27th ed. CLSI supplement M100. Wayne, Pa: CLSI, 2017. https://clsi.org/ Susceptibility Testing. 27th ed. CLSI supplement M100. Want
media/1469/m100s27_sample.pdf (accessed 3 November 2019).

media/1469/m100s27_sample.pdf (accessed 3 November 2019).
5. European Committee on Antimicrobial Susceptibility Testing (EUCAST). Breakpoint tables for . European Committee on Antimicrobial Susceptibility Testing (EUCAST). Breakpoint tables for
interpretation of MICs and zone diameters. Version 8.1, 2018. http://www.eucast.org/fileadmin/src media/PDFs/EUCAST_files/Breakpoint_tables/v_9.0_Breakpoint_Tables.pdf (accessed 3 November 2019).

6. World Health Organization (WHO). Global Antimicrobial Resistance Surveillance System: Manual for early implementation. 2015. https://apps.who.int/iris/bitstream/handle/10665/279656/9789241515061 eng.pdf?ua $=1$ (accessed 3 November 2019).

7. Singh-Moodley A, Perovic O. Phenotypic and genotypic correlation of carbapenememase-producing Enterobacteriaceae and problems experienced in routine screening. S Afr Med J 2018;108(6):495-501. https://doi.org/10.7196/SAMJ.2018.v108i6.12878

8. Lowe M, Kock MM, Coetzee J, et al. Klebsiella pneumoniae ST307 with bla $a_{\mathrm{OXA} A \mathrm{~S} \mid \mathrm{I}}$, South Africa, 2014 2016.Emerg Infect Dis 2019;25(4):739-747. https://doi.org/10.3201/eid2504.181482

9. World Health Organization (WHO). Global Antimicrobial Resistance Surveillance System (GLASS) report: Early implementation 2016 - 2017. 2018. https://apps.who.int/iris/bitstream/hand (GLASS) report: Early implementation 2016 - 2017. 2018. https://apps.who.int/4
le/10665/259744/9789241513449-eng.pdf? sequence $=1$ (accessed 3 November 2019).

10. Perovic O, Ismail H, van Schalkwyk E. Antimicrobial resistance surveillance in the South African public . Perovic O, Ismail H, van Schalkwyk E. Antimicrobial resistance surveillance in the South African pu
sector. South Afr J Infect Dis 2018;33(4):118-129. https://doi.org/10.1080/23120053.2018.1469851

11. Perovic O, Ismail $\mathrm{H}$, van Schalkwyk E, et al. Antimicrobial resistance surveillance in the South African private sector report for 2016. South Afr J Infect Dis 2018;33(4):114-117. https://doi.org/10.1080/23120 053.2018.1482646

Accepted 2 August 2019. 